\title{
A FAHP-FUZZY Approach of Evaluating Banking Service Quality
}

\author{
Xilong Liu ${ }^{1} \&$ Yizeng Chen $^{1}$ \\ ${ }^{1}$ School of Management, Shanghai University, Shanghai, P. R. China \\ Correspondence: Yizeng Chen, School of Management, Shanghai University, Shanghai, 200444, P. R. China. Tel: \\ 86-21-6616-0596. E-mail: mfcyz@shu.edu.cn
}

Received: May 4, $2013 \quad$ Accepted: June 13, $2013 \quad$ Online Published: June 26, 2013
$\begin{array}{ll}\text { doi:10.5539/ijbm.v8n14p158 } & \text { URL: http://dx.doi.org/10.5539/ijbm.v8n14p158 }\end{array}$

\begin{abstract}
With the development of the interest rate liberalization in China, the narrowing of spreads has great influence on China's commercial banks operating income, the commercial banks "innovation" pressure is increasingly urgent. The electronic bank, as the main means of innovation, was being developed rapidly in recent years, which played an important role in reducing the constantly increasing intermediary business income during operation. The electronic banks promote the business innovation, and it is very convenient for the customer service. The purpose of innovation is to improve the quality of service. Bank service quality is an important factor to affect the bank's reputation and an important means of competition among banks. Based on the model of service quality of commercial banks, according to Chinese current situation, the paper puts forward an evaluation method using the FAHP-FUZZY model of service quality evaluation, in order to promote the continuous improvement of commercial banking service quality.
\end{abstract}

Keywords: commercial bank, service quality, FAHP, FUZZY, evaluation

\section{Introduction}

Since the year of 2012, because of the economic downturn and the People's Bank of China (PBC) adjustment of the floating range of interest rate by midyear, one research has shown that the Interest Expense is the most important operating expense for banks (about $85 \%$ ), the narrowing of spreads creates a huge challenge for bank management, also the interest rate liberalization will impact on the profitability of commercial banks. By the end of April, the 2012 annual report of listed banks had showed that the Industrial and Commercial Bank of China, the Agricultural Bank of China, the Bank of China, the China Construction Bank and the Bank of Communications those assets scale was nearly $50 \%$ of the total Chinese banking, and the five banks had realized a net profit of 774.6 billion Yuan, increased 14.9 percent at the same period of last year. The average growth rate of 2012 fell behind the year of 2011 by more than 30 percent. A number of phenomena show that banking has turned into the market-oriented and low-growth industry from the semi-monopolistic and high-growth industry. In the process of declining growth, banks are facing the functional restructuring and the business transformation, that is, banks whose customers are mainly large enterprises begin to serve small businesses. Under the constraints of competition intensifies in the domestic and international interbank, banks will have to adjust customer structure and improve service quality in order to seek for new sources of profit.

Banks' service quality plays an important role in their reputation, which is a main approach during competition among banks as well as the core competence of banks' sustainable development. Therefore, how to improve banks' service quality and the structure of asset quality is an urgent subject in the background of market-oriented interest rate in China.

A lot of researches have proved that the service quality determines the Customer Satisfaction (Fornell, C., Michael, D. J., et al, 1996), and the Customer Satisfaction determines Customer Loyalty (Chunxiao, W., Xiaoyun, H., et al, 2003), which directly or indirectly brings in the profit increase. For example, if the customer loyal rises by $5 \%$, the company's net profit will increase by $25 \% \sim 95 \%$ (Reichhdd, F. F., 1996). As above, the logic is concluded: Service Quality $\rightarrow$ Customer Satisfaction $\rightarrow$ Customer Loyalty $\rightarrow$ Profit.

\section{Literature Review}

The research of service quality began in the 1970s. All researches indicate that the evaluation of service quality largely depends on the customers' psychological cognition because of the characteristics of the service, such as intangibility, heterogeneity, human contact, the process and so on. Perceived Service Quality by Ravald 
Grouroos, the representative of Nordic service quality school, embodies the idea of customers on Service Quality, and thus it can be called "market-oriental quality of service". Grouroos also suggested that the quality of service should be classified into Outcome or Technical Quality and Process Quality (Gronroos, C., 1984). The former highlights the objectivity of the evaluating while the latter emphasizes the subjectivity of the evaluating. Fomell classified the quality of service into Customization (the degree of suppliers' meeting the customers' demands) and Reliability (the stability and accessibility of service from service providers) (Fornell, C., Michael, D. J., et al, 1996), which are similar to Ravald Grouroos's Outcome or Technical Quality and Process Quality. According to Ms. Wen Yanbi's and Mr. Wang Xiaochun's researches, the overall quality of service not only includes hardware quality and software quality but also contains contact fairness, result fairness and procedural fairness; the above-mentioned three fairness and two service qualities equally make up the sub-factors of the overall quality of service(Biyan, W., \& Chunxiao, W., 2005). However, the evaluating process of service quality is the process of the subjective perception of value, during which contact fairness and procedural fairness have a high correlation with Process Quality or Software Quality while result fairness with Technical Quality or Hardware Quality. Hence, the evaluating of service quality remains two main means of Process Quality (or Software Quality) and Technical Quality (or Hardware Quality).

Brands and distribution are very important in the purchase and consumption of tangible products because in most cases consumers cannot have an acquaintance with manufacturers and can only infer from brands and distribution for what manufacturers are like, whereas corporate images (rather than tangible products or brands) are very important to service enterprises in service industry where consumers can see service enterprises themselves as well as the sources of service businesses and the way of operation without the shelter of brands and distribution. Berry found that the corporate image was the driving factor of the successful service enterprises through researching 14 high-performance service businesses (including banks); he also suggested that positive images should be shaped by means of increasing customers' experiences of service and put forward the ways of constructing corporate images by boosting the reputation enterprises, establishing emotion relationship with customers, internalizing brands (which is to deepen the idea of brands in the staff) and so on (Berry, L. L., 2000). Mr. Liu Jun found that the images and service quality of Chinese-funded banks and foreign-invested banks equally affected the cognition of service value. Corporate images, which affect Technical Quality and Process Quality, are accumulated consequences after customers' long-term service experiences (Jun, L., 2004). For this reason, corporate images and quality cognition affect each other.

Scholars construct the measure of service quality largely from the above-mentioned three dimensions (that is Technical Quality, Process Quality and Corporate images). For instance, in the 10 variables of SERVQUAL by Parasuraman, Competence (the staff's knowledge and technique as well as their ability of organization, research and development) and Tangibility (service entities) are relevant to Technical Quality; Credibility(the reliability of service enterprises and the consideration of customers) is associated with Corporate Images; Process Quality relates to Professionalism (the efficiency of the staff's completing service), Responsiveness(the willingness of the staff's providing service), Accessibility (the accessible and convenient contact), Courtesy (politeness, respect, consideration and kindness), Communication (the effective expression and listening), Security (zero risk and privacy) and Empathy (the ability of understanding customers) (Parasuraman, A., Zeithaml, V. A., \& Berry, L. L., 1985). The excellent quality of service can bring customer satisfaction and customer loyalty. Economists like Fornell classify customer satisfaction into overall satisfaction, the satisfaction resulting from the comparison between experience and expected quality as well as the satisfaction resulting from the comparison between experience and ideal quality. Therefore, customer satisfaction results from customers' psychological comparison whose benchmark is expectation. The formation of expectation originates from the previous experience of the application and from the judgment of competitors and ideal status. Customer intentions or behavior loyalty can be measured by repeated purchase. Economists like Gremler think customer satisfaction has a close relationship with the four kinds of customer loyalty (the loyalty of cognition, the loyalty of emotions, the loyalty of intentions and the loyalty of behavior) (Gremler, D. D, Brown, S.W., Bitner, M. J., \& Parasuraman, A., 2001). In order to make a quantitative measurement of the bank's service levels, Mr. Xu Jun and his colleagues made an evaluating from the perspective of factor analysis. They conducted a survey of service levels targeting CMBC and CCB as research objects and preliminarily designed the comparatively overall evaluating system of commercial banks including 8 primary indicators, which are Tangibility, Sensibility, Trust, Reactivity, Assurance, Professionalism, Humanity and Accessibility, and 30 secondary indicators and so on(Jun, X., \& Jiong, Y., 2008).

\section{Methodology}

\subsection{Constructing the Evaluating Indicator System}

Constructing the comprehensive evaluation indicator system is the vital foundation of the fuzzy comprehensive 
evaluation meanwhile the choice of the evaluating indicator directly affects the evaluating conclusion. In this paper, the author refers to the above-mentioned relevant literature, employs the 10 variables of SERVQUAL by Parasuraman, reconstructs Mr. Xu Jun's theory and establishes the evaluating indicator system, which includes three layers, that is to say, the target layer, the main criteria layer and the sub-criteria layer. The target layer is "the comprehensive evaluation of listed banks' service quality"; the main criteria layer is the primary evaluating indicator including technical quality, corporate images and process quality; the sub-criteria layer is the secondary and tertiary evaluating indicator, which is the detail of the main criteria layer. It is shown in Table 1.

Table 1. The comprehensive evaluation indicator system of listed banks' service quality

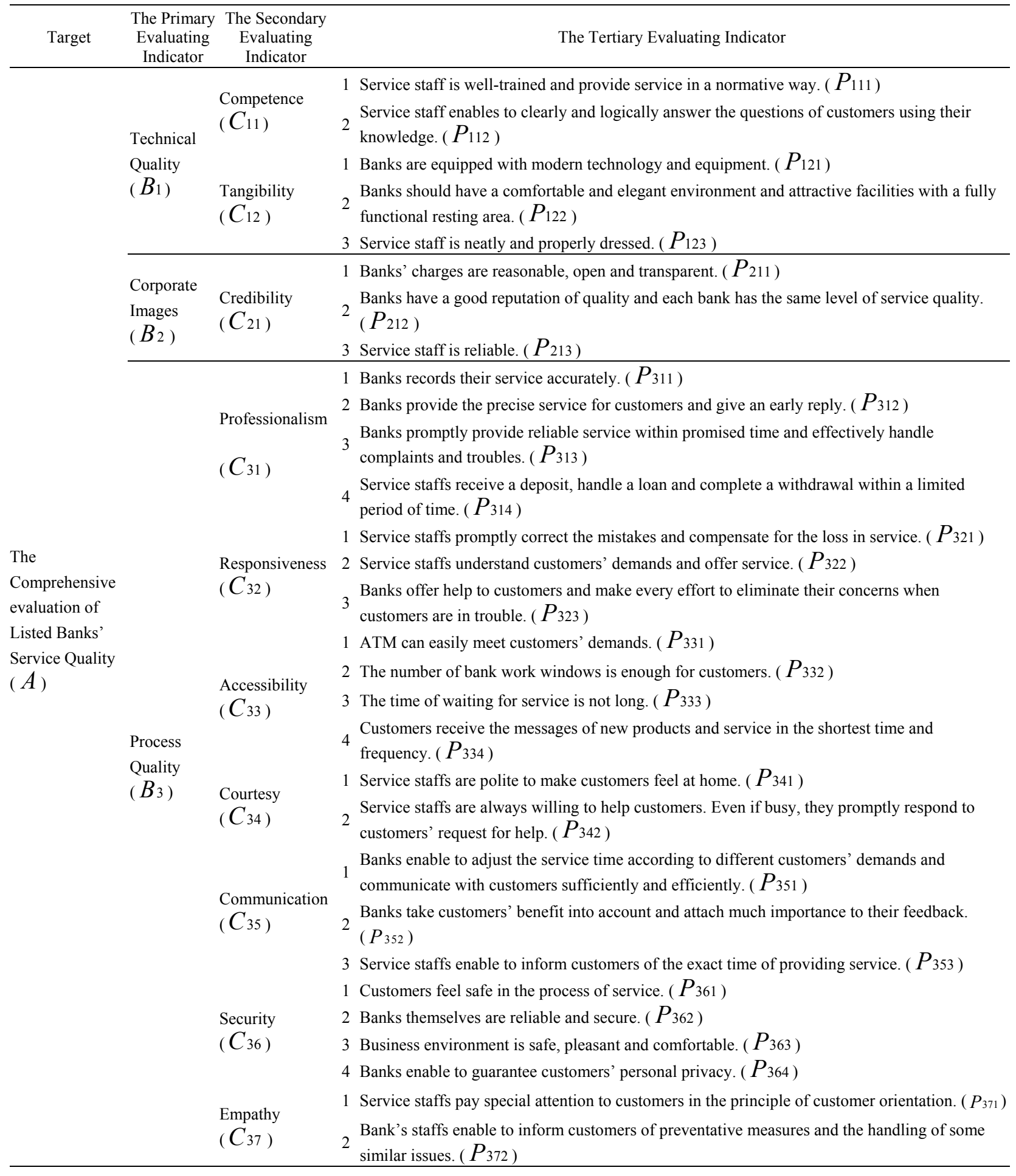




\subsection{Determining the Weight of Each Indicator by Fuzzy Analytic Hierarchy Process (FAHP) Method}

Analytic Hierarchy Process (AHP) is a system analysis method of combining qualitative analysis with quantitative analysis, which was put forward by Professor A.L.Saaty in 1970s, who was an American operational researcher of the University of Pittsburgh. The key process of AHP is to establish judgment matrix, whether the judgment matrix is reasonable or not, it will directly affect the effect of APH. This method can effectively analyze non-sequential relationship between the level of objective criteria system and comprehensive measurement by the decision maker's judgment and comparison. It is widely used in the fields of society, economy and management etc. because the system is simple and practical (Jibin, L., Yang, X., Liangan, H., \& Jiazhong, L., 2006). However, it has the following disadvantages (Jijun, Z., 2000): Firstly, it is difficult to test and judge the consistency of judgment matrix; secondly, there is a significant difference between the consistency of judgment matrix and that of human beings; thirdly, the criteria of the consistency of judgment matrix: $C R<0.1$ lacks the scientific evidence; fourthly, when the judgment matrix is not consistent, its adjustment will be very difficult. Nevertheless, FAHP can overcome the above-mentioned disadvantages and it is simpler and more scientific than the traditional AHP.

FAHP firstly constructs a fuzzy consistent matrix by pairwise comparison of the elements of the same layer. In this paper, if Table 2 is used to scale and $r_{i j}=1-r_{j i}$ is true, the constructed judgment matrix $R=\left(r_{i j}\right)$ will be fuzzy consistent matrix, that is to say, it is unnecessary to test the consistency of matrix. Then according to the character of fuzzy consistent matrix, the weight of the element in each layer $w_{i}$ can be measured as follows.

$$
w_{i}=\frac{1}{n}-\frac{1}{2 a}+\frac{1}{n a} \times \sum_{k=1}^{n} r_{i k}, i \in \Omega
$$

Where, $n$ is the order of $R, \Omega=\{1,2, \cdots, n\}, a=(n-1) / 2$.

Table 2. 0.1 0.9 quantity scale (Yanmei, Z., \& Weihua, L., 2008)

\begin{tabular}{|c|c|c|}
\hline Scale & definition & Description \\
\hline 0.5 & Equally important & Compared with each other, two elements are equally important. \\
\hline 0.6 & Slightly important & $\begin{array}{l}\text { Compared with the other, one element is slightly more important } \\
\text { than the other. }\end{array}$ \\
\hline 0.7 & Obviously important & $\begin{array}{l}\text { Compared with the other, one element is obviously more } \\
\text { important than the other. }\end{array}$ \\
\hline 0.8 & Much more important & $\begin{array}{l}\text { Compared with the other, one element is much more important } \\
\text { than the other. }\end{array}$ \\
\hline 0.9 & Extremely important & $\begin{array}{l}\text { Compared with the other, one element is extremely more } \\
\text { important than the other. }\end{array}$ \\
\hline $0.1,0.2,0.3,0.4$ & Converse comparison & $\begin{array}{l}\text { If comparing the element } a_{i} \text { with the element } a_{j} \text { concludes the } \\
\text { judgment } r_{i j} \text {, then the compared element } a_{j} \text { concludes the } \\
\text { judgment } r_{i j}=1-r_{j i}\end{array}$ \\
\hline
\end{tabular}

\subsection{Evaluating the Object by Fuzzy Comprehensive Evaluation Method}

The advantage of AHP is that it enables the evaluating indicators which are difficult to quantify by other means to be quantitatively analyzed by pairwise comparison, under the condition of the complex structure of judgment targets and the shortage of necessary data. Then it can take the complex evaluating indicators into a clear and easy hierarchical structure which will effectively determine the relative importance of various factors in the evaluating of multi-factor, and to make a further evaluating. However, the disadvange of APH is the shortage of a unitive and specific indicator quantifying method in the process of judging the targets as a whole. Therefore, in practice, the fuzzy analytic hierarchy process and the fuzzy comprehensive evaluation should be combined together to evaluate the bidding units. Namely, first of all, use the fuzzy analytic hierarchy process to calculate the various indicator weights, and then use the comprehensive evaluation in fuzzy mathematics to make a 
comprehensive evaluation.

The fuzzy comprehensive evaluation is to make a comprehensive evaluation of something using the tool of fuzzy mathematics during taking the effect of various factors into consideration (Tao, Z., 2006). We assume that $U=\left\{u_{1}, u_{2}, u_{3}, \cdots, u_{m}\right\}$ is the set of $m$ elements of describing the evaluated object, and $V=\left\{v_{1}, v_{2}, v_{3}, \cdots, v_{n}\right\}$ is the set of $n$ judgments of describing the status of each element.

The evaluating indicator to determine the target are decided by $n$ factors, and can be uniquely defined by $U$, $U=\left\{u_{1}, u_{2}, u_{3}, \cdots, u_{m}\right\}, u_{i}(i=1,2, \cdots, m)$, the influence degree of each $u_{i}$ is difference for determining the level of critical objects. i.e., their weights are difference, Which distribute the weight is one fuzzy subset of $U$, and can be uniquely defined by $\underset{\sim}{W}, \underset{\sim}{W}=\left\{w_{1}, w_{2}, \cdots, w_{m}\right\}$, where $w_{i}$ is the weight of $u_{i}, w_{i} \geq 0, \sum_{i=1}^{m} w_{i}=1$. By evaluating the each single fuzzy factor, the fuzzy comprehensive evaluation matrix can be obtained as follows.

$$
R=\left(\begin{array}{l}
R_{1} \\
R_{2} \\
\vdots \\
R_{n}
\end{array}\right)=\left[\begin{array}{cccc}
r_{11} & r_{12} & \cdots & r_{1 n} \\
r_{21} & r_{22} & \cdots & r_{2 n} \\
\vdots & \vdots & & \vdots \\
r_{m 1} & r_{m 2} & \cdots & r_{m n}
\end{array}\right]
$$

Where $R_{i}=\left(r_{i 1}, r_{i 2}, \cdots, r_{i n}\right)$ is the ith single factor evaluating of $u_{i}$, so $r_{i j}$ indicates that the frequency distribution of ith factor $(1 \leq i \leq m) \quad u_{i}$ in the $j$ th judgment $v_{j}(1 \leq j \leq n)$, and generally make it normalization to satisfy with $\sum_{j=1}^{n} r_{i j}=1$.

The results of comprehensive evaluation can be obtained by the complex calculating as follows.

$$
G=\underset{\sim}{A} \bullet \underset{\sim}{R}=\left(G_{1}, G_{2}, \cdots, G_{n}\right) \in F(V)
$$

Where $G_{j}$ indicates that the level of evaluated subject for the set of judgments. i.e., the membership degree of $v_{j}$ for fuzzy sets $G$. Then starting from the principle of maximum membership degree, in $G=\left(G_{1}, G_{2}, \cdots G_{n}\right)$,

Takes its maximum value as the level of evaluating object, and also may according to the formula of fuzzy vector or the principle of weighted averages, each grade were assigned to a certain score, and normalization (Yonghong, H., \& Sipin, H., 2001).

\section{Comprehensive Evaluations of Banks' QOS}

\subsection{Determining the Weight of Each Indicator by FAHP}

According to the hierarchy structure model in Table 1, make a level's indicator which is relative to previous level's indicator to pairwise comprise by the importance degrees, obtain the fuzzy consistent judgment matrix, the importance degrees of indicator pairwise comprise to determine by the 0.1 0.9 Quantity Scale in Table 2. Then make a level's indicator that relative to previous level's indicator to sort by the importance degrees, obtain the relative weights among all indicators as follows(table $3 \sim$ table 16$)$.

Table 3. The fuzzy consistent judgment matrix and weight of first evaluating indicator $\mathrm{A}$

\begin{tabular}{ccccc}
\hline Indicator $A$ & $B_{1}$ & $B_{2}$ & $B_{3}$ & $w_{A}$ \\
\hline$B_{1}$ & 0.5 & 0.4 & 0.25 & 0.217 \\
$B_{2}$ & 0.6 & 0.5 & 0.35 & 0.317 \\
$B_{3}$ & 0.75 & 0.65 & 0.5 & 0.467 \\
\hline
\end{tabular}


Table 4. The fuzzy consistent judgment matrix and weight of second evaluating indicator $B_{1}$

\begin{tabular}{|c|c|c|c|}
\hline Indicator $B_{1}$ & $C_{11}$ & $C_{12}$ & $w_{B 1}$ \\
\hline$C_{11}$ & 0.50 & 0.40 & 0.404 \\
\hline$C_{12}$ & 0.60 & 0.50 & 0.596 \\
\hline
\end{tabular}

Table 5. The fuzzy consistent judgment matrix and weight of second evaluating indicator $B_{2}$

\begin{tabular}{ccc}
\hline Indicator $B_{2}$ & $C_{11}$ & $\mathcal{W B}_{B 1}$ \\
\hline$C_{11}$ & 0.50 & 1 \\
\hline
\end{tabular}

Table 6. The fuzzy consistent judgment matrix and weight of second evaluating indicator $B_{3}$

\begin{tabular}{ccccccccc}
\hline Indicator $B_{3}$ & $C_{31}$ & $C_{32}$ & $C_{33}$ & $C_{34}$ & $C_{35}$ & $C_{36}$ & $C_{37}$ & $w_{B 3}$ \\
\hline$C_{31}$ & 0.50 & 0.30 & 0.48 & 0.17 & 0.29 & 0.77 & 0.55 & 0.121 \\
$C_{32}$ & 0.70 & 0.50 & 0.64 & 0.65 & 0.24 & 0.11 & 0.71 & 0.146 \\
$C_{33}$ & 0.52 & 0.36 & 0.50 & 0.16 & 0.30 & 0.15 & 0.79 & 0.108 \\
$C_{34}$ & 0.83 & 0.35 & 0.84 & 0.50 & 0.68 & 0.63 & 0.13 & 0.165 \\
$C_{35}$ & 0.71 & 0.76 & 0.70 & 0.32 & 0.50 & 0.88 & 0.48 & 0.183 \\
$C_{36}$ & 0.23 & 0.89 & 0.85 & 0.37 & 0.12 & 0.50 & 0.25 & 0.129 \\
$C_{37}$ & 0.45 & 0.29 & 0.21 & 0.87 & 0.52 & 0.75 & 0.50 & 0.147 \\
\hline
\end{tabular}

Table 7. The fuzzy consistent judgment matrix and weight of third evaluating indicator $C_{11}$

\begin{tabular}{cccc}
\hline Indicator $C_{11}$ & $P_{111}$ & $P_{112}$ & $W_{c 11}$ \\
\hline$P_{111}$ & 0.50 & 0.30 & 0.296 \\
$P_{112}$ & 0.70 & 0.50 & 0.700 \\
\hline
\end{tabular}

Table 8. The fuzzy consistent judgment matrix and weight of third evaluating indicator $C_{12}$

\begin{tabular}{ccccc}
\hline Indicator $C_{12}$ & $P_{121}$ & $P_{122}$ & $P_{123}$ & $W_{c 12}$ \\
\hline$P_{121}$ & 0.5 & 0.35 & 0.55 & 0.300 \\
$P_{122}$ & 0.65 & 0.5 & 0.75 & 0.467 \\
$P_{123}$ & 0.45 & 0.25 & 0.5 & 0.233 \\
\hline
\end{tabular}

Table 9. The fuzzy consistent judgment matrix and weight of third evaluating indicator $C_{21}$

\begin{tabular}{ccccc}
\hline Indicator $C_{21}$ & $P_{211}$ & $P_{212}$ & $P_{213}$ & $w_{c 21}$ \\
\hline$P_{211}$ & 0.50 & 0.20 & 0.79 & 0.330 \\
$P_{212}$ & 0.80 & 0.50 & 0.33 & 0.376 \\
$P_{213}$ & 0.21 & 0.67 & 0.50 & 0.295 \\
\hline
\end{tabular}


Table 10. The fuzzy consistent judgment matrix and weight of third evaluating indicator $C_{31}$

\begin{tabular}{cccccc}
\hline Indicator $C_{31}$ & $P_{311}$ & $P_{312}$ & $P_{313}$ & $P_{314}$ & $w_{c 31}$ \\
\hline$P_{311}$ & 0.50 & 0.80 & 0.59 & 0.71 & 0.350 \\
$P_{312}$ & 0.20 & 0.50 & 0.68 & 0.18 & 0.176 \\
$P_{313}$ & 0.41 & 0.32 & 0.50 & 0.18 & 0.152 \\
$P_{314}$ & 0.29 & 0.82 & 0.82 & 0.50 & 0.322 \\
\hline
\end{tabular}

Table 11. The fuzzy consistent judgment matrix and weight of third evaluating indicator $C_{32}$

\begin{tabular}{ccccc}
\hline Indicator $C_{32}$ & $P_{321}$ & $P_{322}$ & $P_{323}$ & $w_{c 32}$ \\
\hline$P_{321}$ & 0.50 & 0.40 & 0.34 & 0.245 \\
$P_{322}$ & 0.60 & 0.50 & 0.83 & 0.478 \\
$P_{323}$ & 0.66 & 0.17 & 0.50 & 0.277 \\
\hline
\end{tabular}

Table 12. The fuzzy consistent judgment matrix and weight of third evaluating indicator $C_{33}$

\begin{tabular}{cccccc}
\hline Indicator $C_{33}$ & $P_{331}$ & $P_{332}$ & $P_{333}$ & $P_{334}$ & $w_{c 33}$ \\
\hline$P_{331}$ & 0.50 & 0.12 & 0.79 & 0.69 & 0.267 \\
$P_{332}$ & 0.88 & 0.50 & 0.27 & 0.32 & 0.245 \\
$P_{333}$ & 0.21 & 0.83 & 0.50 & 0.77 & 0.302 \\
$P_{334}$ & 0.31 & 0.68 & 0.23 & 0.50 & 0.203 \\
\hline
\end{tabular}

Table 13. The fuzzy consistent judgment matrix and weight of third evaluating indicator $C_{34}$

\begin{tabular}{cccc}
\hline Indicator $C_{34}$ & $P_{341}$ & $P_{342}$ & $w_{c 34}$ \\
\hline$P_{341}$ & 0.50 & 0.61 & 0.610 \\
$P_{342}$ & 0.39 & 0.5 & 0.390 \\
\hline
\end{tabular}

Table 14. The fuzzy consistent judgment matrix and weight of third evaluating indicator $C_{35}$

\begin{tabular}{ccccc}
\hline Indicator $C_{35}$ & $P_{351}$ & $P_{352}$ & $P_{353}$ & $w_{c 35}$ \\
\hline$P_{351}$ & 0.50 & 0.73 & 0.81 & 0.511 \\
$P_{352}$ & 0.27 & 0.50 & 0.23 & 0.168 \\
$P_{353}$ & 0.19 & 0.77 & 0.50 & 0.321 \\
\hline
\end{tabular}

Table 15. The fuzzy consistent judgment matrix and weight of third evaluating indicator $C_{36}$

\begin{tabular}{cccccc}
\hline Indicator $C_{36}$ & $P_{361}$ & $P_{362}$ & $P_{363}$ & $P_{364}$ & $w_{c 36}$ \\
\hline$P_{361}$ & 0.50 & 0.15 & 0.17 & 0.48 & 0.134 \\
$P_{362}$ & 0.85 & 0.50 & 0.29 & 0.84 & 0.331 \\
$P_{363}$ & 0.83 & 0.71 & 0.50 & 0.35 & 0.314 \\
$P_{364}$ & 0.52 & 0.16 & 0.65 & 0.50 & 0.221 \\
\hline
\end{tabular}

Table 16. The fuzzy consistent judgment matrix and weight of third evaluating indicator $C_{37}$

\begin{tabular}{cccc}
\hline Indicator $C_{37}$ & $P_{371}$ & $P_{372}$ & $w_{c 37}$ \\
\hline$P_{371}$ & 0.5 & 0.42 & 0.420 \\
$P_{372}$ & 0.58 & 0.5 & 0.580 \\
\hline
\end{tabular}




\subsection{Using Fuzzy Comprehensive Evaluation Method to Evaluate the Listed Banks'Service Quality}

\subsubsection{Determing the Estimation Scales}

The evaluation scales were decided by the evaluation committee that includes 10 experts of technical and economic aspects, and given the set of judgments $V=\{$ best, better, good, bad, worse $\}$.

4.2.2 Determing the Relation Matrix between the Criteria Layer of $C$ and $V$

Take $C_{11}$ for example, we assume that $P_{111}=\{0.2,0.4,0.2,0.1,0.1\}$ and $P_{112}=\{0.2,0.3,0.2,0.2,0.1\}$, where, Take $P_{111}$ for example, means $20 \%$ of the experts of the evaluation committee determined the Banks' Service Quality is best. $40 \%$ are better, $20 \%$ are good, and $10 \%$ are bad; the rest of $10 \%$ are worse. So we can obtain the relation matrix $R_{c 11}$ between the criteria layer of $C_{11}$ and $V$ as follows.

$$
R_{c 11}=\left[\begin{array}{c}
P_{111} \\
P_{112}
\end{array}\right]=\left[\begin{array}{lllll}
0.2 & 0.4 & 0.2 & 0.1 & 0.1 \\
0.2 & 0.3 & 0.2 & 0.2 & 0.1
\end{array}\right]
$$

4.2.3 One-Stage Fuzzy Comprehensive Evaluation

As we have calculated the relative weights of $A, B, C$ hierarchies by FAHP method before, so we can obtain the One-stage fuzzy comprehensive evaluation about $C_{11}$ as follows.

$$
\begin{aligned}
& C_{11}=w_{c 11} \cdot R_{c 11} \\
& =\{0.2960 .700\} \bullet \bullet\left[\begin{array}{lllll}
0.2 & 0.4 & 0.2 & 0.1 & 0.1 \\
0.2 & 0.3 & 0.2 & 0.2 & 0.1
\end{array}\right] \\
& =(0.20,0.33,0.20,0.17,0.10)
\end{aligned}
$$

Where, it means $20 \%$ of the experts of the evaluation committee determined the Banks' Service Quality is best. $33 \%$ are better, $20 \%$ are good, and $17 \%$ are bad; the rest of $10 \%$ are worse.

In a similar way, the other of one-stage fuzzy comprehensive evaluation about $C$ hierarchy as follows.

$$
\begin{aligned}
& C_{12}=(0.17,0.40,0.20,0.13,0.10) \\
& C_{21}=(0.13,0.40,0.24,0.17,0.06) \\
& C_{31}=(0.18,0.42,0.20,0.17,0.03) \\
& C_{32}=(0.20,0.40,0.25,0.13,0.03) \\
& C_{33}=(0.18,0.41,0.25,0.13,0.05) \\
& C_{34}=(0.16,0.40,0.20,0.14,0.10) \\
& C_{35}=(0.15,0.40,0.20,0.18,0.07) \\
& C_{36}=(0.19,0.42,0.20,0.14,0.05) \\
& C_{37}=(0.20,0.44,0.26,0.10,0.00)
\end{aligned}
$$

4.2.4 Multi-Stage Fuzzy Comprehensive Evaluation

From the result of the previous step, we can obtain the fuzzy matrix between the criteria layer of $C$ and the set of judgments $V$ as follows.

$$
\begin{aligned}
R_{B 1} & =\left(\begin{array}{l}
0.20,0.33,0.20,0.17,0.10 \\
0.17,0.40,0.20,0.13,0.10
\end{array}\right) \\
R_{B 2} & =(0.13,0.40,0.24,0.17,0.06)
\end{aligned}
$$




$$
R_{B 3}=\left(\begin{array}{l}
0.18,0.42,0.20,0.17,0.03 \\
0.20,0.40,0.25,0.13,0.03 \\
0.18,0.41,0.25,0.13,0.05 \\
0.16,0.40,0.20,0.14,0.10 \\
0.15,0.40,0.20,0.18,0.07 \\
0.19,0.42,0.20,0.14,0.05 \\
0.20,0.44,0.26,0.10,0.00
\end{array}\right)
$$

The weight of the criteria layer of $B$ have been calculated from the previous step by FAHP as follows:

$$
w_{B 1}=(0.404,0.596)
$$

(see Table 4)

Based on $B_{1}=w_{B 1} \bullet R_{B 1}$, we can calculate the Comprehensive Evaluation of the criteria layer of $B$ as follows.

$$
\begin{gathered}
B_{1}=w_{B 1} \bullet R_{B 1} \\
=(0.404,0.596)\left[\begin{array}{l}
0.20,0.33,0.20,0.17,0.10 \\
0.17,0.40,0.20,0.13,0.10
\end{array}\right] \\
=(0.18,0.37,0.20,0.15,0.10)
\end{gathered}
$$

In a similar way, the other fuzzy comprehensive evaluation about $B$ hierarchy can be calculated as follows.

$$
\begin{aligned}
& B_{2}=(0.13,0.40,0.24,0.17,0.06) \\
& B_{3}=(0.18,0.41,0.22,0.14,0.05)
\end{aligned}
$$

As above, we can obtain the fuzzy matrix between the layer of targets $A$ and the set of judgments $V$ as follows.

$$
R_{A}=\left(\begin{array}{l}
0.18,0.37,0.20,0.15,0.10 \\
0.13,0.40,0.24,0.17,0.06 \\
0.18,0.41,0.22,0.14,0.05
\end{array}\right)
$$

The weights of the target layer of $A$ have been calculated from the previous step by FAHP as follows.

$$
w_{A}=(0.217,0.317,0.467)
$$

Finally, we can obtain the result of fuzzy comprehensive evaluation by complex calculating as follow,

$$
\begin{aligned}
& \underset{\sim}{G=} \underset{\sim}{A} \bullet \underset{\sim}{R}=w_{A} \bullet R_{A} \\
= & (0.16,0.40,0.22,0.15,0.06)
\end{aligned}
$$

As above which indicated that $16 \%$ of the experts determined the bank's QOS are best; $40 \%$ are better, $22 \%$ are good, $15 \%$ are bad, the rest of $6 \%$ are worse. According to the maximum membership principle, the bank's QOS should be concluded as better.

\section{Conclusion}

From the analysis and examples of this paper, it is convenient and suitable for banks to apply the AHP and the fuzzy comprehensive evaluation to the evaluation of banks' QOS, which can help banks to make the evaluating more reasonable and largely reduce the effect of the judges' personal subjective factors. Thus the judges can make a more objective evaluating, which is of great significance to promote the fairness, the openness and the impartiality of evaluating.

Banks'QOS is the customers' value judgment. Through analyzing the indices and the factors of affecting banks' QOS, the paper indicates how banks improve their quality of service. Apart from the evaluating indices of banks' QOS, banks should systematically improve their QOS from the bank's product and service through constant innovation, so that banks' service can really meet customers' expectation and constantly enhance the attraction of customers in the increasingly fierce market competition.

\section{Acknowledgments}

The work described in this paper is supported by a grant from the National Nature Science Foundation of Chinese (project no. NSFC 71272177/G020902) and the funds "Innovation Program of Shanghai Municipal Education Commission (project no.12ZS101). 


\section{References}

Berry, L. L. (2000). Cultivating Service Brand Equity. Academy of Marketing Science, 28. http://dx.doi.org/10.1177/0092070300281012

Biyan, W., \& Chunxiao, W. (2005). The Impact of Service Fairness on Customer Relationship. Nankai Business Review, 3.

Chunxiao, W., Xiaoyun, H., \& Biyan, W. (2003). An Empirical Study of the Relationship between Customer Satisfaction and Loyalty. Nankai Business Review, 4.

Fornell, C., Michael, D. J., Eugene, W. A., Jaesung, C., \& Barbara, B. (1996). The American Customer Satisfaction Index: Description, Finding, and Implications. Journal of Marketing, 60(4), 7-18. http://dx.doi.org/10.2307/1251898

Gremler, D. D., Brown, S. W., Bitner, M. J., \& Parasuraman, A. (2001). Customer Loyalty and Satisfaction: What Resonates in Service Comexts. Working Paper.

Gronroos, C. (1984). A Service Quality Model and Its Marketing Implications. European Journal of Marketing, 12(8), 588-601. http://dx.doi.org/10.1108/EUM0000000004985

Jibin, L., Yang, X., Liangan, H., \& Jiazhong, L. (2006). Research on the Priorities of Fuzzy Analytical Hierarchy Process. Systems Engineering-Theory \& Practice, 2, 107-112.

Jijun, Z. (2000). Fuzzy Analytical Hierarchy Process. Fuzzy Systems and Mathematics, 14(2), 80-88.

Jun, L. (2004). Service Value Perception and the Correlations with Its Antecedents: An Empirical Analysis with Foreign Banks' Clients and Local Chinese Banks' Clients Comparison. Economic Research, 1.

Jun, X., \& Jiong, Y. (2008). Evaluation System of Bank Service Quality and Data Analysis. China Management Informationization, 11(19).

Parasuraman, A., Zeithaml, V. A., \& Berry, L. L. (1985). A Conceptual Model of Service Quality and Its Implications for Future Research. Journal of Marketing, 49. http://dx.doi.org/10.2307/1251430

Reichhdd, F. F. (1996). The Loyalty Effect. Harvard Business School Press.

Tao, Z. (2006). Management common method. Tianjin: Tianjin University Press.

Yanmei, Z., \& Weihua, L. (2008). Enhanced FAHP and its application to task scheme evaluation. Computer Engineering and Applications, 44(5), 212-214.

Yonghong, H., \& Sipin, H. (2001). Fuzzy comprehensive evaluation. Beijing: Science Press.

\section{Copyrights}

Copyright for this article is retained by the author(s), with first publication rights granted to the journal.

This is an open-access article distributed under the terms and conditions of the Creative Commons Attribution license (http://creativecommons.org/licenses/by/3.0/). 